\title{
Ressignificações da vida ribeirinha: das margens do rio Tocantins ao Assentamento Mirindiba em Araguaína - Tocantins - Brasil
}

\section{Re-significations of ribeirinha life: from the Tocantins river to the Mirindiba Settlement in Araguaína - Tocantins - Brazil}

Eliseu Pereira de Brito - Doutor em Geografia, pela Universidade Federal de Goiás (UFG). Professor Adjunto do Curso de Geografia da Universidade Federal do Tocantins (UFT). E-mail: eliseubrito@uft.edu.br

Henrique Martins da Silva - Graduação em Geografia, pela Universidade Federal de Tocantins (UFT). Membro do Grupo de Estudos Geográficos da Amazônia e Tocantins da UFT. E-mail: henriquematins24@gmail.com

\section{Resumo}

Este texto se propôs a estudar as ressignificações ribeirinhas, tomando por escala espacial de estudo o assentamento Mirindiba, formado por famílias que foram expulsas dos seus territórios com o enchimento do lago da usina hidrelétrica Estreito, em Babaçulândia, Tocantins, Brasil. Utilizamos o método exploratório para a construção da análise, com pesquisa de campo, uso de mapa falado e entrevistas. Os ribeirinhos viviam numa ilha chamada São José, no rio Tocantins, cultivavam em roças de vazantes e praticavam a pesca artesanal. Com a desterritorialização, a conquista do assentamento foi uma forma de buscar a continuidade da vida ribeirinha, mas a dinâmica dos lugares é diferente e os força para novas territorialidades. A forma de produzir é impulsionada por fatores técnico-científicos e o território tem novos atores, que estão em redesempresas. É no contexto da territorialização que os sujeitos buscam ressignificar as coisas e os lugares, até para uma manutenção das suas identidades ribeirinhas.

\section{Palavras-chave}

Ribeirinhos. Rio Tocantins. Ressignificações. Lugares. Assentamento.

\begin{abstract}
We propose to study the ribeirinhas resignifications in the Mirindiba settlement. This is formed by families that were expelled from their territories with the filling of the lake of the Estreito Hydroelectric Power, in Babaçulândia, Tocantins. We used the exploratory method for the construction of the analysis, with field research, use of spoken map and interviews. These ribeirinhos dwellers lived on an island called São José, in the Tocantins River, cultivated in lowland fields and practiced artisanal fishing. With the deterritorialization, the conquest of the settlement was a way of seeking the continuities of the ribeirinha life, but the dynamics of the places are different and force them towards new territorialities. The way of producing is driven by technical-scientific factors and the territory has new actors who are in network-companies. It is in the context of territorialization that the subjects seek to reframe things and places, even for the maintenance of their ribeirinhas identities.
\end{abstract}

\section{Keywords}

Ribeirinhos. Tocantins river. Resignifications. Places. Rural Settlement. 


\section{INTRODUÇÃO}

O rio Tocantins teve as suas margens ocupadas ainda no século XVIII, no Estado do Tocantins, por indivíduos que utilizavam os recursos hídricos como elementos de produção e subsistência, a navegação e as vazantes. Os povos que têm algum tipo de vínculo e se utilizam do rio, seja na plantação de vazante ou para as atividades pesqueiras, são denominados, na região, de ribeirinhos.

Os sujeitos que estudamos nesta pesquisa são ribeirinhos que habitavam a ilha de São José, próxima da cidade Babaçulândia, Tocantins. Eram sujeitos camponeses, que praticavam a pesca artesanal e a agricultura de vazante e foram expulsos dos seus lugares com o enchimento do lago da UHE Estreito em 2010 e assentados próximos à cidade de Araguaína, Tocantins. No assentamento Mirindiba buscam reconstruir as suas vidas. É no bojo da reconstrução dos seus modos de vida que propomos, com esta pesquisa, compreender as ressignificações ribeirinhas. Tivemos como objetivo buscar, na percepção ribeirinha, elementos que retratam as permanências do modo de vida e observações do território, pelas histórias e medos que retratam a resistência identitária.

Para atender os objetivos utilizamos de uma pesquisa qualitativa, com método descritivo exploratório, buscando, a partir da observação e entrevistas com os ribeirinhos, entender as permanências com as observações respaldadas nos instrumentos do Diagnóstico Rural Participativo (DRP) (VERDEJO, 2006). Utilizamos nuvens de palavras para melhor interpretar as falas dos entrevistados.

O texto foi construído por fontes primárias e secundárias, com entrevistas e embasamento em autores que proporcionaram o melhor entendimento sobre o tema central e que levaram à melhor percepção dos elementos presentes no modo de vida ribeirinho, buscando analisar as resistências e permanências ribeirinhas no novo local de vivência, com fotografias, desenhos e depoimentos que estabelecem uma ligação de significados.

\section{EM BUSCA DE UMA HISTÓRIA DE OCUPAÇÃO DAS MARGENS DO RIO TOCANTINS}

A ocupação do estado do Tocantins teve importante contribuição advinda da dinâmica produzida pela navegação no rio Tocantins, realizada por barqueiros, canoeiros, ribeirinhos, oficiais de guarnições navais e indígenas. O rio serviu como via para o transporte de mercadoria e pessoas desde o início da ocupação não indígena do território. 
Para Palacín e Moraes (2001), foi pelo rio Tocantins que mineradores avançaram sobre a região sudeste do Tocantins. Trata-se de uma área do complexo cristalino, planalto Araguaia-Tocantins (GOMES, 1966), onde houve a descoberta de garimpos de ouro como o de São Luís, atual cidade de Natividade, em 1734; Ouro Podre, atual Arraias, em 1740; Chapada, em 1740, e Conceição, em 1741 (BARBOSA; GOMES; TEIXEIRA NETO, 2005). Todos esses garimpos foram conectados ao rio Tocantins pelos seus afluentes, como o rio Manoel Alves da Natividade, rio Palma e Paranã. Havia uma rede de arraiais de estilo dendrítica, em que a fluidez foi estabelecida, conforme a orientação hidrográfica.

Contudo, é preciso levar em consideração que essa rede, de certa forma, foi interrompida em 1740, com a proibição do transporte fluvial no rio Tocantins - uma medida que visava coibir o tráfico do ouro das minas do norte de Goiás para a cidade de Belém (PA), rota para a Europa, uma vez que esses mineradores tinham forte influência na cidade. No auge do ouro na região foram queimados até barcos em estaleiros, evitando qualquer fluidez no território (BRITO, 2016). O rio Tocantins ficou fechado para a navegação até a crise do ouro e, posteriormente, ao final dos anos de 1750, foi realizado apenas um fechamento sem tanta vigilância de tráfego.

A expansão do garimpo colonial de ouro de aluvião fora das margens do rio Tocantins proporcionou a formação de presídio (guarnições militares para auxiliar no transporte fluvial) e portos que tornaram cidades ribeirinhas. Destacase a formação de Porto Real em 1738 e Barra da Palma em 1740, que ficam a $20 \mathrm{~km}$ das margens do rio, no encontro dos rios Palma e Paranã (BARBOSA; GOMES; TEIXEIRA NETO, 2005). Esses arraiais se tornaram portos importantes para a dinâmica territorial. $\mathrm{O}$ desfecho poderia ter sido diferente se a navegação do rio não tivesse sido bloqueada, uma vez que concentraria riquezas extraídas do período auge do garimpo. A forma como se deu o garimpo no norte de Goiás impossibilitou que a riqueza do minério tivesse pujança e ficasse demonstrada nas igrejas, casas, cemitérios, entre outros locais.

Com a crise do ouro em meados de 1750 (PALACÍN; MORAES, 2001), o norte de Goiás teve cinquenta anos de isolamento e crise, apenas modificado o cenário econômico com os incentivos propostos por Joaquim Teotônio Segurado, em 1804, para o funcionamento da navegação comercial do rio Tocantins. Esse período marcou um rearranjo regional e algumas vilas foram criadas, como a Boa Vista, em 1818, e Filadélfia, em 1857 (BARBOSA; GOMES; TEIXEIRA NETO, 2005).

Houve a introdução de um fluxo migratório que não chegou pelo rio Tocantins, uma vez que, na sua maioria, foram migrantes vindos do Nordeste, 
principalmente dos estados do Maranhão, Piauí e Bahia, como demonstrado por Brito (2016). Para Brito e Shimasaki (2020), houve uma expansão das ocupações de terras nas "bordas" da floresta amazônica, área de Transição do Cerrado e Amazônia, incentivada pelo extrativismo vegetal do látex no final do século XIX e início do século XX.

Há que se frisar que essa ocupação foi rarefeita pelo território por estar muito ligada aos caminhos de boiadas e do extrativismo do látex da mangabeira. Mangabeira (Hancornia speciosa) é uma arvore do Cerrado, produtora de um fruto comestível pelos povos cerradeiros e dá um leite que, defumado, vira borracha. No Jalapão, região conhecida pelos terrenos arenosos do leste do Tocantins, a procura pelo látex da mangabeira produziu uma corrida migratória da Bahia e Piauí, tanto para a ocupação das terras como para o trabalho intermitente do extrativismo do látex.

Os caminhos das boiadas ou apenas dos retirantes, na sua maioria, dos desapropriados da terra, direcionaram-se para as regiões norte do Tocantins e oeste do rio Tocantins. A frente pioneira tratada por Teixeira Neto (2002) e a "Geografia do Babaçu” (VALVERDE, 1985) são muito elucidativas do processo de ocupação que ocorreu na região do Bico do Papagaio. Esse é um caminho para pensar a ocupação das áreas de transição entre o Cerrado e a Amazônia, como bem lembrado por Ab’Sáber (2003) e Machado (1992).

As bandeiras verdes direcionaram para os lugares/municípios que hoje se denominam de Muricilândia, Santa Fé do Araguaia e Aragominas. Esses povos, dirigidos por profecias e crenças, ocuparam esses lugares como se fosse a terra prometida (MARTINS, 1996). A história da ocupação girou em torno de uma profecia de uma senhora migrante, que se tornou ponto central da ocupação espacial. Essa é uma forma de interpretação mítica no catolicismo popular, que tem alcance quando sobreposto a interpretações bíblicas e que tem impacto direto sobre a posse do território, construindo, com isso, formas de mediações da leitura e interpretação do mundo, mediante uma visão fundada no espaço vivido e na memória (CONCEIÇÃO; BRITO, 2019).

Dos movimentos importantes dessa frente pioneira, um direcionará a transformação do espaço, a fim de introduzir novos usos do espaço, o que possibilita o que Machado (1992) denominou de fronteira agrícola de ocupação com a introdução de novas técnicas, principalmente para os usos do solo. Nesse caso, foi necessária a derrubada da floresta e a sua substituição por pastos ou lavouras. Esse movimento produziu novas dinâmicas nas redes de centralidades no norte do Tocantins. Brito (2009) ressaltou que houve um deslocamento no período da construção da rodovia Belém-Brasília (porção norte da BR-14 - 
oficialmente chamada de estrada Transbrasiliana) dos centros das margens do rio Tocantins para as margens da rodovia. Valverde e Dias (1967) mostraram nos seus estudos que na dinâmica produzida no território, com a abertura dessa rodovia, vários lugarejos foram criados para atender o fluxo de passageiros, que se deslocaram do transporte hidroviário para o rodoviário. Aquino (2002) afirma que a rodovia decretou uma crise no transporte hidroviário e nas cidades ribeirinhas.

Nas margens do rio Tocantins, uma crise se assolou nas cidades e a vida ribeirinha se reinventou. Como se trata de terras de solos pobres em nutrientes, principalmente no norte do Tocantins, com cobertura de neossolos quartzarênicos, as fertilidades dos solos permanecem pela dinâmica produzida pelo rio. As vazantes, terras fertilizadas durante as cheias dos rios, eram/são os locais de plantação ribeirinha (BRITO, 2018; BRITO; SHIMASAKI, 2020). Nessas terras fertilizadas se planta a melancia, abóbora, arroz, feijão, milho, dentre outros alimentos. Esse é o local da sobrevivência ribeirinha.

\section{MUNDO RIBEIRINHO NA ILHA DE SÃO JOSÉ}

Para Cunha (2000, p. 19), "no universo da pesca é possível evidenciar um conjunto de significados simbólicos impressos à água pelo pescador artesanal." Isso evoca os sentidos dados à água como encantos e medos, corporifica a vida e a estranheza vivida nos mitos, nas bravuras, nas tempestades ou calmaria. As águas para um pescador são cheias de mistérios, histórias e lendas. Para Silva (2000), o pescador distingue dois mundos: o seco e o das águas. O seco é fixo, previsível, o das águas é imprevisível, instável, indomável.

Segundo Diegues (2007, p. 01), "Em muitas sociedades chamadas 'primitivas' a água doce das fontes, dos riachos e rios é símbolo de vida ao passo que as águas do mar simbolizam o perigo e a morte". Para o autor, as águas são campo fértil para os contos mitológicos, vistas de acordo com as crenças, habitat e sobrevivência. Os povos amazônicos vivem a sua vida social controlados pelas cheias e secas dos rios: ou podem interagir mais ou devem manter-se em isolamento, devido ao perigo que o rio representa para a navegação de pequenas embarcações no período de cheias.

Localizada a $30 \mathrm{~km}$ da cidade de Babaçulândia, Tocantins, a ilha de São José tinha $10 \mathrm{~km}$ de extensão e 2,5 km de largura, com uma área aproximada de $15 \mathrm{~km}^{2}$, conforme medidas da imagem do satélite. O rio Tocantins abriu dois canais: o direito com $680 \mathrm{~m}$ de largura e o esquerdo com $472 \mathrm{~m}$ de largura. Antes de formar a ilha, o rio afundou o seu canal em terrenos sedimentares, que lhes proporcionava um transporte de sedimentos em suspensão, rico em nutrientes, depositando-os no período das enchentes no seu leito maior e na ilha de São José. 
O rio Tocantins é cristalino, de acordo com a classificação das cores dos rios da Amazônia, proposta por Sioli (2006). São rios que têm as suas nascentes em terrenos arqueanos e transportam grande quantidade de partículas de rochas em suspensão e musgos. As águas são claras, de coloração azulada. É um rio que tem a cava do seu leito bem encaixado no Planalto Central e apresenta, nesse percurso, gradiente com desníveis muito baixos. No caso da ilha de São José, o canal da direita era o principal; para tanto, servia como linha divisória dos estados do Maranhão e Tocantins. A forma da ilha era semelhante a um diamante, formando uma extensa praia, com depósitos de areia na ponta superior, alargando-se ao meio e afinando-se na parte inferior.

Conforme Roldão e Ferreira (2019), o clima do Tocantins é Aw - clima de savana (classificação de Köppen) e possui uma estação chuvosa, que se estende por seis meses de chuvas, de novembro a abril. "Os principais sistemas geradores de chuvas no Tocantins são a Zona de Convergência Intertropical (ZCIT) e a Zona de Convergência do Atlântico Sul (ZCAS)" (ROLDÃO; FERREIRA, 2019, p. 1163). As chuvas de verão produzidas por essas massas de ar são responsáveis pelas cheias do rio Tocantins. Como lembrou Sioli (2006), um rio age como sistema renal da paisagem, pois ele drena toda área de uma paisagem e nas suas águas é possível encontrar toda essa dinâmica geológica, pedológica e biológica nos sedimentos transportados.

No rio Tocantins, os sedimentos transportados eram depositados em áreas que inundavam com as cheias, fertilizando o solo utilizado pelos ribeirinhos para a plantação de cereais. A fertilidade produzida pelo rio dava aos moradores fartura de alimentos.

As farturas da produção agrícola e de peixes abasteciam a feira de Babaçulândia nos finais de semana. A entrevistada 01 (Babaçulândia, abr. 2019) afirmou que nos finais de semana, cada ribeirinho buscava trazer das suas roças os seus produtos para comercializar na feira, como abóboras, quiabo, mandioca, arroz, feijão, frutas e o pescado. De acordo com a entrevistada 03 (Assentamento Mirindiba, mar. 2020), a família plantava roça e os filhos também praticavam atividades de pesca artesanal. O pescado era levado para ser comercializado nas cidades próximas, Estreito (MA), Carolina (MA) e Babaçulândia (TO). Para a própria alimentação, a forma de pescar era diferente, tanto na distância que percorriam, como no tempo de permanência no rio. "Estávamos ali querendo merendar, pegava a varinha e descia por rio, voltava com o peixe para fritar e comer com farinha de puba" (informação verbal) ${ }^{1}$.

Informação verbal fornecida pela entrevistada 03, no Assentamento Mirindiba, em março de 2020. 
Com um álbum de fotos, o entrevistado 04 (Assentamento Mirindiba, fev. 2020) recorda e descreve a vida na ilha, que tinha um cenário paisagístico, composto de uma formação do cerrado lato sensu tipo palmeirais-babaçuais. Por morar no lado oeste da ilha, o pôr do sol sobre o rio era o espetáculo que se assistia ao entardecer. As serenatas dos barulhos das águas lhes serviam como uma terapia para acalmar-se depois da lida do dia, quando não saía para pescar. Toda a vida girava em torno do rio Tocantins, ali era o caminho, o lugar de lazer, o lugar de trabalho. Nas fotos, o entrevistado 04 faz questão de ressaltar o seu pomar e a abundância das frutas que colhia, tornando a sua dieta diversificada. Segundo o entrevistado, as terras boas eram as da beira de rio, que foram inundadas pelas águas da UHE Estreito. As das chapas são terras difíceis, inclusive, ele luta para manter o seu pomar devido às doenças que dão nos frutos, como ele bem frisou, nas mangueiras e laranjeiras.

A comunidade estava espacialmente organizada ao longo do rio, conforme o desenho na Figura 1. Na enchente de 1980, muito lembrada por todos os ribeirinhos da região, as águas expulsaram a maioria da população da área, mas produziram uma fertilidade muito grande na ilha e houve, na época, uma fartura de alimentos. "Na enchente de 1980, nosso barraco foi inundado e foi preciso ir para o outro lado do rio pra casa de nossos parentes" (informação verbal) ${ }^{2}$. Conforme relatos dos moradores, ter acesso ao rio Tocantins era uma garantia de liberdade na mobilidade pelas águas, que vai ao encontro do que Bonnemaison (1987) afirmou sobre os territórios de errância, possível mediante a fixação e a mobilidade dos indivíduos. É importante frisar que todos os indivíduos tinham acesso ao rio e imediatamente ao campo de várzeas fertilizados nas cheias.

Ter acesso ao rio, de certa maneira era uma possibilidade de viajar, de pescar e de ter o lazer no rio. No centro da ilha, os canais abandonados formavam várzeas que alagavam no transbordar do rio e era nesses lugares que os sujeitos plantavam as suas lavouras de arroz, feijão, milho, melancia, dentre outros alimentos. Nas terras não alagadas, eles cultivavam a mandioca e outras culturas que demandavam maior tempo para o estágio de colheita.

Conforme o entrevistado 02 (Babaçulândia, abr. 2019), as festas e as temporadas de praias animavam o lugar. $\mathrm{Na}$ ilha se formava uma praia muito utilizada para acampamento de banhistas, que gostavam da temporada de praia de águas doces em junho e julho, no rio Tocantins. A festa de São José era o principal festejo da comunidade. Um cortejo descia da ilha até a cidade de Babaçulândia, em agradecimento às dádivas oferecidas pelo santo à comunidade.

2 Informação verbal fornecida pela Entrevistada 01, em Babaçulândia, em abril de 2019. 
Os entrevistados são unânimes em apontar os rompimentos do modo de vida, a partir do anúncio da construção da hidrelétrica Estreito. A mansidão do tempo das águas do rio, que ditava o calendário da pesca e plantação, foi alterada pela construção da hidrelétrica. $O$ trabalho de camponês foi reinventado e substituído por temporário assalariado, na construção de obras da usina.

Figura 1 - Representação artística da ilha de São José no rio Tocantins

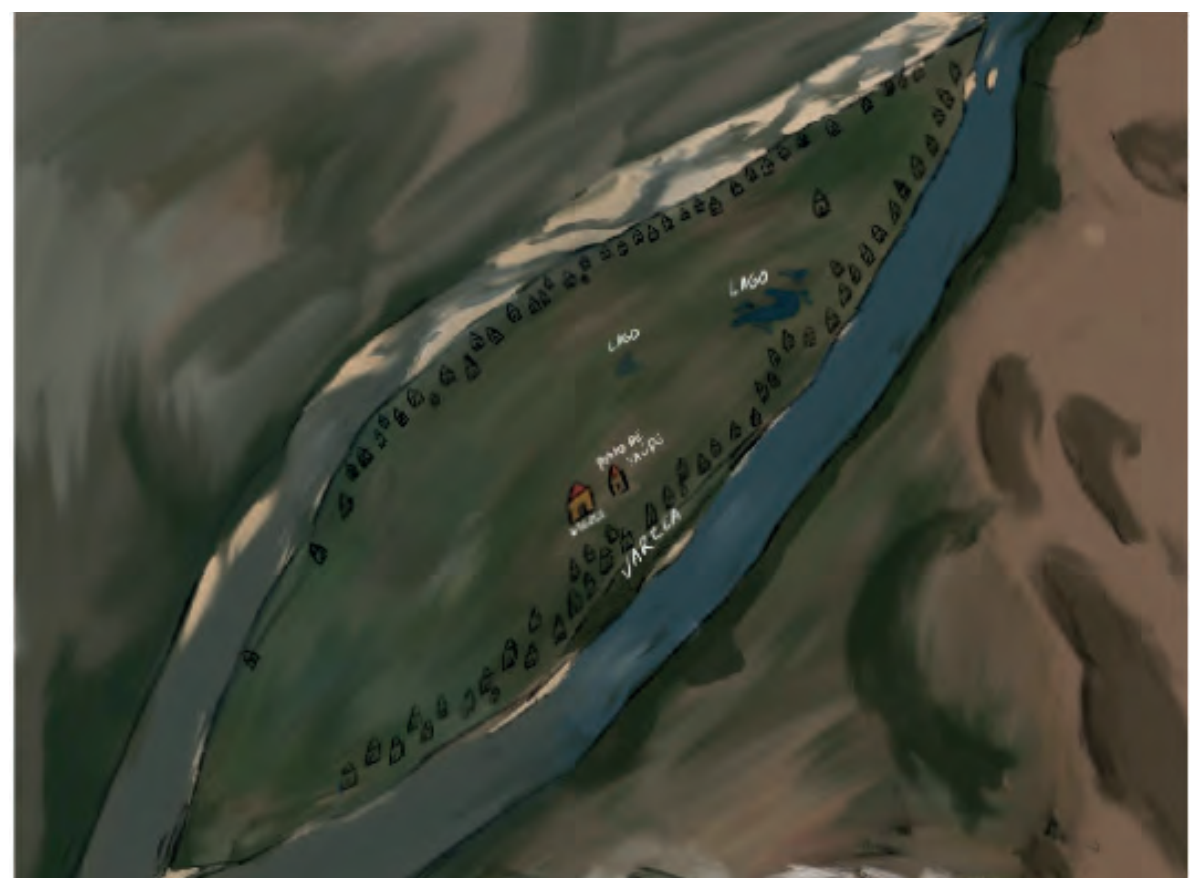

Nota: Representação conforme Entrevistada 03 (mar. 2020) e Entrevistada 01 (mar. 2020).

Fonte: Arte de Gabriel Almeida da Silva ${ }^{3}$ (2020)

A construção de hidrelétricas tem sido o maior fator de desorganização dos povos ribeirinhos. A formação de lago é invasiva das suas terras de vazantes e, quando ocorre, sempre é um fator de expulsão involuntária, sendo a retirada forçada pelo enchimento do lago. Dessa forma, os modos de vida ribeirinhos têm sido alterados pelo impacto da fronteira técnica do capital para a produção de energia com as construções de usinas hidrelétricas (UHE), no rio Tocantins. $\mathrm{O}$ avanço da fronteira da agroenergia no cerrado tocantinense se intensificou nos anos 2000, período que coincide com o início das construções, no estado, de

3 Graduando em Geografia, bolsista da Iniciação Cientifica - PIBIC/UFT. Membro no laboratório GEADH - Grupo de Estudos Agrários e Ciências Humanas. A arte da Figura 1 foi realizada no dia 21 de maio 2020 e feita com tinta guache e giz de cera. 
hidrelétricas no rio Tocantins, que já totalizam quatro usinas em funcionamento: a UHE Estreito, a UHE Luís Eduardo Magalhães - Lajeado, a UHE São Salvador e a UHE Peixe-Angical. Os lagos daí resultantes submergiram os territórios dos ribeirinhos, sujeitos tocantinenses e maranhenses ou migrantes de outros estados (BRITO, 2018).

Focamos a análise na Usina Hidrelétrica Estreito, que foi inaugurada em 2012 no norte do Tocantins e sul do Maranhão, concretizando um projeto do Plano Decenal de Expansão e Oferta de Energia Elétrica (2000 a 2009) do Governo Federal e a UHE Estreito. Em julho de 2002, as comunidades ribeirinhas começaram a ser notificadas da construção da obra e convidadas para audiência. A vida na ilha começou a ficar incerta (ENTREVISTADO 04, Assentamento Mirindiba, fev. 2020). Em dezembro de 2006, o Instituto Brasileiro do Meio Ambiente e dos Recursos Naturais Renováveis (IBAMA) emitiu a licença para a construção da obra e, em junho de 2007, oficialmente, a hidrelétrica começou a ser construída. A construção ficou a cargo do Consórcio Estreito Energia (CESTE) - formado pela Suez Energy International (Estados Unidos), Vale (Brasil), BHP Billiton Metais (Anglo-Australiana), Alcoa (Brasil) e Camargo Corrêa Energia (Brasil) (CESTE, 2016).

Os ribeirinhos começaram a se organizar em busca de garantias de direito ao território. Conforme entrevistada 03 (Assentamento Mirindiba, mar. 2020), uma forma de resistir à construção da usina foi fazer uma marcha de ribeirinhos até a cidade de Estreito - MA, buscando romper os isolamentos impostos pelas autoridades locais e regionais. O canteiro de obras gerado pela hidrelétrica invisibilizou os ribeirinhos, que passaram a ser empecilhos para o "progresso" e para a modernização do território. Houve uma propagação de informações por parte de políticos e empresários locais quanto à importância da obra na geração de emprego e no desenvolvimento local, principalmente articulado com um discurso da soberania energética para alavancar uma industrialização da região. Tais discursos surgiram rapidamente para blindar a política contrária à construção de barragem e, na rapidez que eles surgiram, desapareceram, sem deixar uma esperança para a população da concretização de tais benefícios (BRITO, 2018).

Em dezembro de 2010, o lago começou a encher e todas as 74 famílias já estavam retiradas das suas propriedades. "Eles chegaram e disseram que era pra eu sair. Quando vi queria me tirar a força, eu exigi que mandassem barcos para me buscar. Tirei tudo que podia, até os pedaços de madeira" (informação verbal) 4 . Com o enchimento do lago inundando as terras, não havia mais como resistir,

Informação verbal fornecida pelo Entrevistado 04, no Assentamento Mirindiba, em fevereiro de 2020. 
apenas assistir à formação do lago. O ribeirinho pescador que permanecesse nas margens do lago precisava interromper o seu trabalho por algum tempo, devido à toxicidade das águas em materiais decompostos. Para os expulsos das margens do lago, a vida precisava ser reinventada em lugares longínquos, como no assentamento Mirindiba, distante $107 \mathrm{~km}$ das margens do lago.

Com o lago formado em outubro de 2012, a então presidente da República, Dilma Rousseff, acionou simbolicamente a oitava unidade geradora e inaugurou a UHE Estreito, que passou a operar com a capacidade de 1.087 MW. Para o Brasil foi a disponibilidade de mais energia produzida; para os ribeirinhos foi uma drástica mudança de vida.

\section{NO ASSENTAMENTO MIRINDIBA}

As resistências ribeirinhas de lutas pelo direito de sobrevivência e ao território produziram uma conquista da terra ao invés de apenas uma carta de crédito oferecida pelo CESTE. Segundo a entrevistada 03 (Assentamento Mirindiba, mar. 2020), era preciso garantir que não ficariam fora da terra e a única forma seria por um assentamento ribeirinho. Houve resistência do grupo CESTE em aceitar a proposta demandada, que impôs limites, como a apresentação de possível terra à venda. Os próprios ribeirinhos buscaram apresentar a indicação de possível terra para a aquisição, intermediando uma negociação entre o fazendeiro e o CESTE. A fazenda era denominada de Mirindiba e estava na microbacia hidrográfica do ribeirão Gurgueia, afluente do rio Lontra, distante $7 \mathrm{~km}$ da rodovia BelémBrasília e cerca de $40 \mathrm{~km}$ do centro da cidade de Araguaína. O assentamento foi constituído por 18 famílias em 04 de agosto de 2010 (COSTA, 2019).

Trata-se de um terreno de chapada em área de transição cerrado/floresta amazônica. Há pequenas quantidades de manchas de latossolos e domínio de argissolos, conforme observação em campo e apresenta uma área de cobertura secundária com formação de pastos para a pecuária bovina, com algumas áreas preservadas de floresta ombrófila aberta. Entre as glebas, um pequeno córrego intermitente drena as terras do assentamento. Para o abastecimento das casas são utilizados poços artesianos e caixas d'água.

Os ribeirinhos assentados têm uma diversidade nas suas plantações, de mandioca à abóbora, cultivam nas suas roças de toco uma variedade de alimentos, que servem para as suas dietas alimentares. Eles também cultivam plantas medicinais, como o mastruz, hortelã e sabugueiro. Os saberes dos povos tradicionais são ricos em conhecimento das plantas e as suas eficácias contra doenças. Para Costa (2019), 
Faz parte da natureza do campesinato a variedade na produção; mesmo quando está submetida às normas do mercado, a unidade familiar busca produzir em menor quantidade produtos que, teoricamente, deveriam ser buscados no mercado. Um camponês relatou que até mesmo o adubo ele evita comprar, pois utiliza os dejetos do gado como fertilizante; fato raro, pois na maioria das propriedades o uso de intensivos é baseado na compra de químicos encontrados na cidade (COSTA, 2019, p. 119 - 120).

Para o autor supracitado, as formas de produção no assentamento dos ribeirinhos são camponesas. O trabalho é focado na suficiência alimentar, realizado por membros da família e por atividades remuneradas e de mutirão entre eles. Devido à demanda por insumos e técnicas para a produção agrícola, é observável uma diferença entre plantações e diversidades de culturas nas roças/ lavouras. Para Costa (2019, p. 116), "Se na ilha o adubo era proporcionado pelos ciclos da natureza, sobretudo pelas cheias do rio Tocantins que proporcionava a acumulação de húmus; agora é necessária a utilização de elementos químicos que precisam ser adquiridos no mercado".

Quanto à criação de animais, a maioria cria galinhas soltas nos quintais e um assentado já trabalha assessorado pela Agência de Defesa Agropecuária (ADAPEC) e Universidade Federal do Tocantins (UFT) no aprimoramento das técnicas da avicultura. Para o Entrevistado 04 (Assentamento Mirindiba, fev. 2020), houve treinamento com os assentados pelo órgão estadual e federal para a criação de aves. Essas informações fizeram com que ele construísse um galpão para instalar o galinheiro com chocadeiras, com ambientes de criação, recriação e terminação, em um manguezal para o crescimento livre do frango. Os frangos e as galinhas são vendidos em feiras de Araguaína ou direto para abatedouros municipais.

Os criatórios de bovinos e suínos são para atender as próprias necessidades no consumo de carne e na venda do leite para redes de laticínios de Araguaína. A maioria desses assentados utiliza a carne de porco e a sua banha na culinária. Isso se deve, a não disponibilidade do azeite de coco Babaçu, uma vez que a referida palmeira é escassa na área do assentamento.

Foi descrito pelos assentados que a produção no assentamento entra na lógica do mercado e são fiscalizados. Há uma exigência de vacinar o gado, de prestação de contas do rebanho. Para a entrevistada 03, esse é um fator de insegurança.

Só em você pensar que você vai lá na ADAPEC, nós têm, num sei quantas galinha, nós cria. Já num é mais nossa. Já num tem mais direito. Quantas galinha? Quantos pinto nasce num ano? Tudo hoje tem um controle. Então, pra nós foi a pior coisa por quê lá não tinha controle. O controle era nós que fazia, de num devorar as coisas, num devastar, num desmatar, num pegar o peixe pra destruir. Pegar só o tantim de comer, de você num 
matar caça pra você vender, se matar você come. Então tudo lá era regrado, tudo era cuidado. Agora não, como num tem, quando vai é pegar tudo de uma vez, senão o outro vem e já toma. Até na alimentação você não tem sossego. Não tem o controle. A sua tranquilidade de que isso aqui é meu e ninguém num meche. Lá no rio era de todo mundo, nós todos mundo usava, tinha cuidado, o controle, pegava os peixe pra vender mais dizia: óia! Vou levar só esse tanto. Hoje não, você tem que pegar pra comer, pra vender, pra derramar, porque senão num vem mais (informação verbal) ${ }^{5}$.

O mundo no assentamento é diferente na produção e na distribuição. Para os produtores de leite e mandioca, é preciso se submeter aos arranjos territoriais no controle de empresas, que dominam o monopólio do leite, no preço tabelado, na qualidade exigida. Na produção de mandioca e dos seus derivados há uma lógica de venda, apesar de alguns desses assentados estarem com venda direta em feiras de Araguaína, mas o preço é determinado pelo mercado.

Para Garzon e Silva (2019), a forma como as populações ribeirinhas são retiradas dos seus mundos, principalmente por construções de hidrelétricas e na orientação das hidrovias, dificulta os seus modos de existência. Para os autores, esses sujeitos ficam às margens de uma sobrevivência, como ribeirinhos pelo fato de terem sido expulsos do rio ou mesmo de não terem acesso ao lago para pescar, plantar ou navegar.

\section{RESSIGNIFICANDO O MUNDO: UMA TÁBUA DE LAVAR ROUPA, UMA REDE E UM TANQUE DE CRIAR PEIXES}

O mundo do rio cheio de mistérios, encantos e nostalgia se acabou. Distante $80 \mathrm{~km}$ do rio Tocantins, que agora é um lago, os ribeirinhos tiveram que se adaptar em um assentamento na chapada drenada por pequenos córregos. O mundo das águas foi trocado por terras secas na serra do Estrondo, forçando adaptações até então não conhecidas pelos ribeirinhos. "Nos primeiros anos vieram uns agrônomos aqui nos ensinar plantar arroz, e não é que deu muito arroz? Mas, depois, não conseguimos nada mais na colheita" (informação verbal $)^{6}$, afirmou o entrevistado 04 se referindo aos primeiros anos de vida no assentamento. $\mathrm{O}$ tempo do trabalho e da vida no assentamento, apesar de ainda ser dominado pela dinâmica do clima tropical (Aw), tem outro comando que não mais é o rio e as suas cheias e secas, é o da fertilização química do solo e das chuvas sobre a chapada.

\footnotetext{
Informação verbal fornecida pela Entrevistada 03, no Assentamento Mirindiba, em março de 2020.

6 Informação verbal fornecida pelo Entrevistado 04, no Assentamento Mirindiba, em fevereiro de 2020.
} 
Para Bonnemaison $(1987,2012)$, os homens constroem geossímbolos, que podem ser uma pedra de primeira aparição que determina um lugar de encontro do homem com a terra, ou um lugar de ritual onde os homens e mulheres dançam e tomam cava (uma bebida aborígene de Vanuatu - Oceania). Em parte, esses são lugares fixos, na compreensão do território como solo; em outro entendimento, do território como instância. A contribuição, principalmente, dos olhares do autor sobre "Tana", é que os lugares estão nos sentidos dados pelas pessoas nas experiências com o espaço. Holzer (2019) afirma que o lugar não é sinônimo de local; ele é vivido, é vivenciado.

As vivências dos sujeitos no rio Tocantins e na ilha de São José fizeram com que sujeitos, uma vez removidos e de forma lenta no tempo, pois consideramos que as incertezas da habitação na ilha vieram ainda em 2002 nas primeiras notificações e se alongou até 2010 com o enchimento do lago da UHE Estreito, tivessem um sentimento de perda gradativa do seu território. Então, ainda em 2002, eles passaram a lutar pelos seus direitos ao uso do território: "Fomos até Estreito numa marcha buscar nossos direitos" (informação verbal) ${ }^{7}$. Essa era uma forma de resistir contra a investida do Estado e das empresas sobre a tomada dos seus territórios. De certa maneira, essa resistência fez com que se aumentasse o apego ao lugar. Houve o reconhecimento do território como espaço de vida e compreensão de que, se perde o território, pode-se perder a existência, como afirmou Bonnemaison (1986).

$\mathrm{Na}$ ilha, o território era uma ancestralidade dos sujeitos e isso denotava segurança na posse e no documento de registro da terra. No assentamento, a própria posse gera medo: "ainda hoje tem isso, só em saber que ela é uma empresa que nunca deu o documento, aí a gente tem exatamente porque a terra não é nossa, a terra não é nossa" (informação verbal) ${ }^{8}$. Para esses sujeitos, se com a posse foram expulsos de suas terras, sem o documento no assentamento tudo é incerto. Estamos tratando, nessa construção, da ideia de que há territórios e, segundo Haesbaert (1995), ao mesmo tempo em que há uma desterritorialização ocorre uma reterritorialização, na qual são os indivíduos que se desterritorializam e constroem novos territórios.

$\mathrm{Na}$ organização da produção no uso do solo e na articulação política com novos atores como as universidades e a Agência de Defesa Agropecuária do Tocantins (ADAPEC), os ribeirinhos construíram novas redes e tessituras, na medida que determinam os lugares, o poder e as ações dos sujeitos no assentamento.

\footnotetext{
Informação verbal fornecida pela Entrevistada 03, no Assentamento Mirindiba, em março de 2020.

8 Informação verbal fornecida pela Entrevistada 03, no Assentamento Mirindiba, em março de 2020 .
} 
Na busca por encontrar símbolos que lhes dão um sentido de "identidade de permanência" (BRITO, 2016), alguns objetos são possuidores de sentido pelos sujeitos. Segundo Bonnemaison (2012, p. 292):

Os símbolos ganham maior força e realce quando se encarnam em lugares. O espaço cultural é um espaço geossimbólico, carregado de afetividade e significações: em sua expressão mais forte, torna-se território-santuário, isto é, um espaço de comunhão com um conjunto de signos e de valores.

O autor ressalta os geossímbolos como lugares de representação, que podem ser um jardim sagrado ou mesmo os itinerários dos povos dos mares e das florestas. Há uma busca por sentido de um lugar nos fatos marcantes, como a dança embaixo de uma árvore ou mesmo o rochedo de orientação. Foi nessa perspectiva que identificamos os sentidos atribuídos ao rio Tocantins, em que os assentados passaram a representar seu território.

Os ribeirinhos assentados buscaram dar continuidade às suas atividades com a terra, adaptando-se a uma nova lógica do trabalho com o solo (COSTA, 2019). Esses também trouxeram objetos de representação do rio Tocantins ou das suas lidas: uma tábua de pequizeiro com a forquilha de aroeira, uma rede de pesca e um tanque de peixe.

No leito de um córrego intermitente, uma tábua chama atenção de quem passa na estrada. Com 3 metros de extensão por 50 centímetros de largura de madeira Jatobá, é utilizada por dona Maria da Ilha para lavar roupa (Figura 2).

Figura 2 - Tábua de Jatobá utilizada para lavar roupas no Assentamento Mirindiba

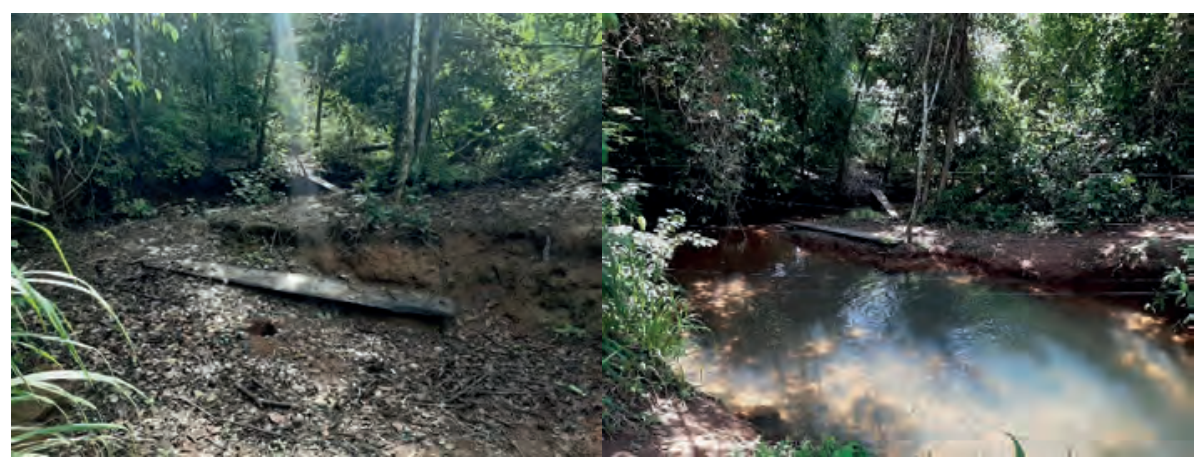

Foto: Autores (set. 2019 e fev. 2020) ${ }^{9}$

A prática de lavar roupa nos rios é muito utilizada por mulheres tocantinenses. Sousa (2019, p. 15) afirma que:

9 As fotos foram tiradas em setembro de 2019 e em fevereiro de 2020. Trata-se de um córrego intermitente, chamado pelos moradores de grota. 
Não se pode negar que as lavadeiras são mulheres de sorte, pois elas têm o privilégio de lavarem roupas em meio à natureza e, enquanto trabalham, podem ver barcos passando no meio do rio, pescadores que também servem de companhia para elas, diferentes espécies de aves à procura de peixes e passeando em meio à mata, às margens do rio [...].

No Tocantins, essas mulheres são chamadas de lavadeiras de roupa; na maioria das vezes não fazem com fim econômico, mas como afazeres domésticos. Ao longo do rio são vistas reunidas, lavando roupas nas margens do rio Tocantins ou Araguaia.

Em uma referência à tábua no assentamento, segundo a entrevista 03:

Aquela tábua é um retrato, eu trouxe da ilha. Eu trouxe a minha tábua do rio. Aquela é Jatobá. Aquela dali mesmo não era do rio porque a outra eu tirei, levei pra casa porque era pequena e eu tinha medo da água levar. Eu levei ela e coloquei como tampando o chiqueiro das galinhas. Aquela tábua me serviu pra muitas coisas e ela sempre vai ter utilidade. Coloquei ela ali e toda hora estou fechando os ninhos das galinhas. Aquela tábua que coloquei lá no córrego eu tirei aqui no Mirindiba mas fiz um retrato da outra pois tinha medo da água levar a que eu trouxe do rio. É um retrato da outra. Pra você ter uma ideia, eu trouxe a tábua e a furquia que a tábua estava. É minha furquia, eu vou levar. Ela é do tempo da minha vó essa furquia, de aroeira. Eu coloco ela de pé, ela representa aqui tudo que eu fazia (informação verbal) ${ }^{10}$.

O medo de perder a tábua de pequizeiro (Figura 3), que era herança da sua avó, levou dona Maria da Ilha a criar uma réplica, onde ela pode lavar as roupas. Mesmo com o córrego secando, ter a tábua ali é uma lembrança do rio.

Figura 3 - Tábua de pequizeiro e forquilha de aroeira, uma herança da família

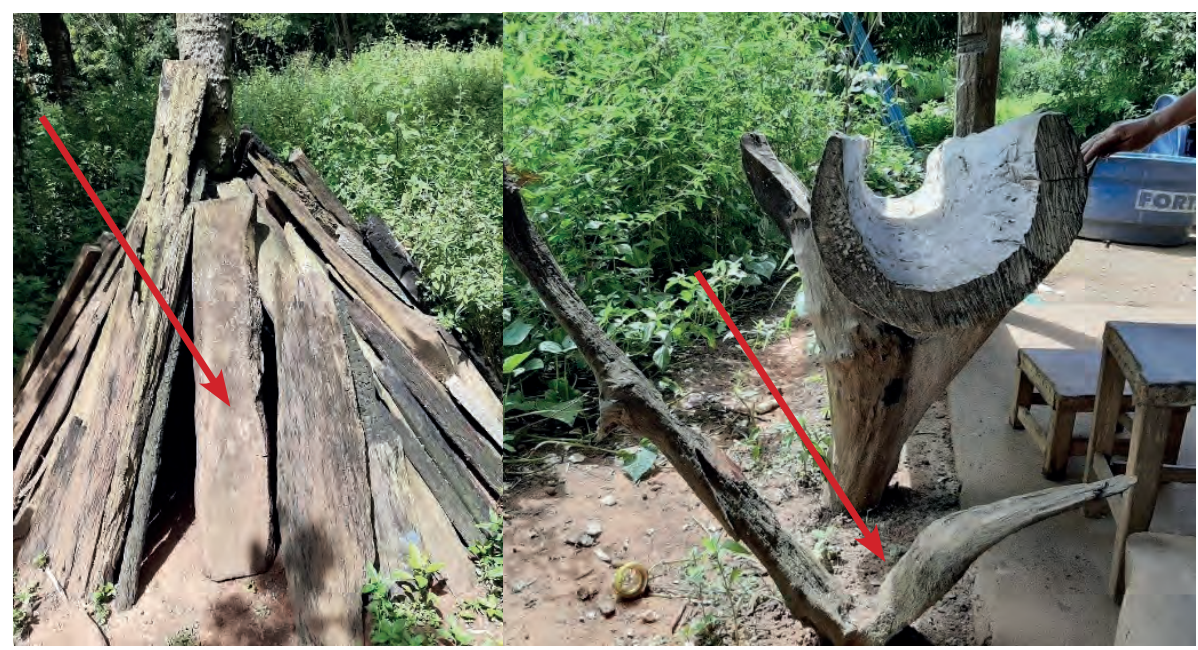

Foto: Autores (fev. 2020)

10 Informação verbal fornecida pela Entrevistada 03, no Assentamento Mirindiba, em março de 2020. 
Segundo a entrevistada 03, a tábua:

Leva sentimento e tristeza. $\mathrm{Na}$ mesma hora que fico alegre lá naquela tábua, eu fico triste, pois me leva a ver o que eu tinha lá no Tocantins, era o mundo de águas. Hoje me sinto como numa cacimba. Não sei se você sabe o que é? A cacimba era um local onde a gente abria um poço e botava a mandioca dentro de molho. A gente abria aquele poço daquele tamanho lá e botava mandioca pra amolecer, tirar a casca e ralar. Então ele me trazia o retrato de duas coisas, um que era um poço de botar mandioca e também aquela vida ali era nossa origem de lavar roupa. Tal ponto que eu até hoje nunca consigo lavar roupa em tanque, né. Agüinha da torneira. Eu boto uma tábua, boto uma bacia e ali eu lavo a roupa. É uma recordação e uma tristeza da vida que a gente tinha. Porque sempre dizia, lá tinha uma dificuldade, subir ladeira, descer ladeira, ir pro rio de canoa, pra Babaçulândia - 6 horas de barcos não é brincadeira, 12 horas de barco, aí era uma dificuldade a mais. Mas era uma tranquilidade, você tinha tudo isso por conta. Hoje aqui tem uma facilidade bastante, mas se torna uma dificuldade, pois nós não temos mais nosso rio, aquela alimentação que nós tinha, aquela praia que nós brincava, né; tem torneira, mas você não pode nem caminhar porque é uma torneira em cima da outra. Eu sempre considero que é uma vantagem e uma desvantagem (informação verbal) ${ }^{11}$.

Lavar roupa na tábua no rio é uma cultura ribeirinha. Muitas lavadeiras acreditam que a roupa fica mais macia quando lavada nas águas do rio, outras acreditam que é um momento de socialização entre elas, sendo um vínculo de amizades pretéritas. Para outras, o trabalho é mais prazeroso nas margens do rio. No assentamento não há um agrupamento das mulheres para lavar roupa; a tábua representa apenas um passado da vida ribeirinha.

Contudo, não são apenas as mulheres que buscam nos objetos as permanências da vida ribeirinha. Os homens também buscam reconstruir as práticas ribeirinhas, principalmente a da pesca, seja ela na construção de um tanque para criatório dos peixes ou mesmo na fabricação e manutenção das redes de pesca (Figura 4).

11 Informação verbal fornecida pela Entrevistada 03, no Assentamento Mirindiba, em março de 2020. 
Figura 4 - Tarrafa de pescaria e um tanque de criação de peixes para o consumo

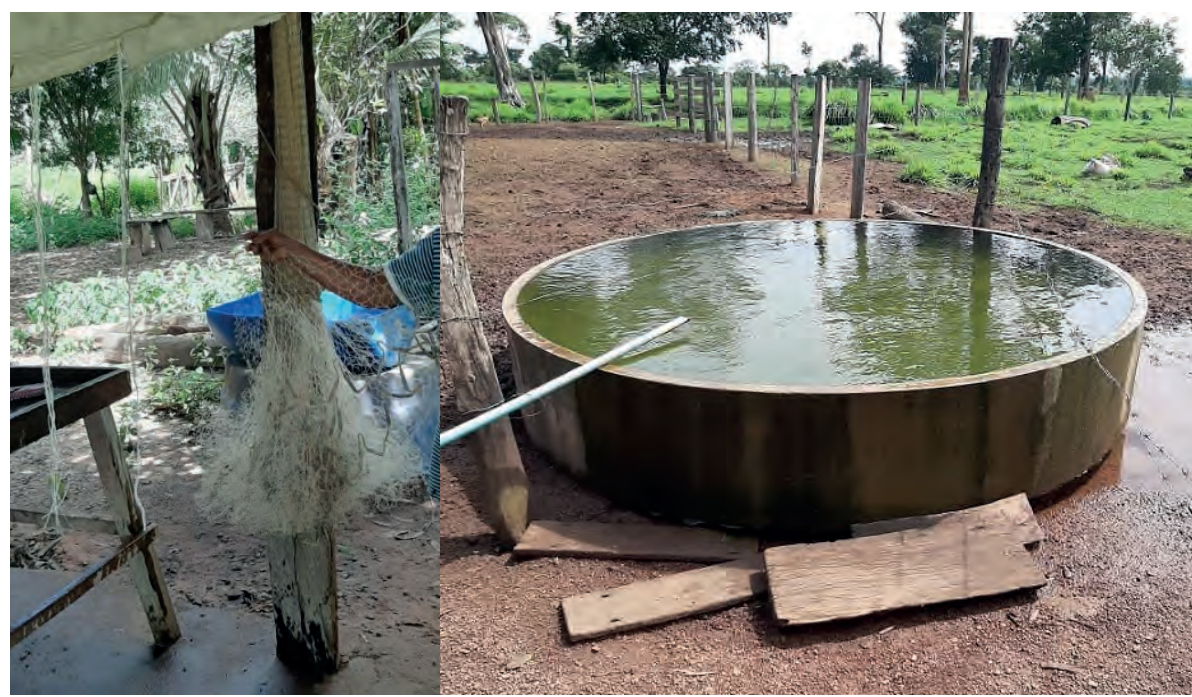

Foto: Autores (set. 2019 e fev. 2020)

Segundo a entrevistada 03, o seu filho trouxe as tarrafas de pescaria e fabrica, de vez em quando, redes para pescar, para não perder a tradição. A pescaria é uma diversão e, ao mesmo tempo, uma lembrança e ato de sobrevivência, uma forma de comer o peixe, uma carne apreciada pelos ribeirinhos.

Porque naquela Gurguéia ali de vez em quando tem água, aí vem o peixe ali. Aí eles fizeram. Aí eles vão lá, porque nas Gurguéia fica os peixes né? Aí no inverno às vezes cria água, aí os peixe sobe e, eles conseguem pegar o peixe, e também pra num acabar a tradição, porque pra ele foi a pior coisa do mundo foi ele ter saído de junto dos peixes, de junto das praias. Ele trouxe o pedaçim de rede, de tarrafa, era uma lembrança dele, né? (informação verbal) $^{12}$.

Contudo, há os que buscam de forma mais aprimorada trazer o cotidiano do rio para a vida no assentamento. Para o entrevistado 04 (Assentamento Mirindiba, fev. 2020), ter um tanque de peixe é a possibilidade de comer um peixe fresco, pescado na hora, como fazia no rio. A entrevistada 03 (Assentamento Mirindiba, mar. 2020) afirma que, no rio, pegar o peixe era questão de necessidade: deu vontade de comer um peixe, pegava a vara ou tarrafa, descia para o rio e depois de 20 minutos retornava com os peixes para comer. Imitar a vida ribeirinha no assentamento é uma expressão de que a identidade ribeirinha ainda permanece viva nos indivíduos. É uma forma seletiva da apropriação da identidade, segundo Sciolla (2010).

12 Informação verbal fornecida pela Entrevistada 03, no Assentamento Mirindiba, em março de 2020. 
Entre histórias e territórios, esses sujeitos construíram as suas identidades ribeirinhas e buscaram uma permanência, ainda que fragilizada. O apego aos objetos e ao modo de vida é uma forma de preservar e lembrar o passado na ilha e resistir a uma imposição de mudança no espaço e tempo no assentamento.

\section{CONSIDERAÇÕES FINAIS}

A ocupação das margens do rio Tocantins aconteceu há mais de dois séculos, incentivada por uma migração espontânea, dirigida ou direcionada. Esse talvez seja um caminho para se pensar as áreas de transição para além de apenas um contato entre biomas, mas também como espaço de fronteira do humano e do conflito. As águas, minérios e terras sempre foram alvos do capital na região e motivo de violência.

A vida ribeirinha na ilha de São José tinha uma temporalidade controlada pelo clima nas cheias e secas do rio. A plantação, a colheita, a pescaria e a navegação estavam, de certa maneira, ligadas à vida nos rios. A fertilização das terras era feita pelas cheias que depositavam húmus nas vazantes. A tradição de plantar, de navegar, de lidar com a natureza e dela extrair a sobrevivência era passada de pais para filhos.

A conquista do assentamento representou um não rompimento com a terra/solo, mas a desterritorialização dos indivíduos foi inevitável. Eles perderam os geossímbolos da ilha e buscam, em coisa como uma tábua ou mesmo pescar no ribeirão ou criar peixes, imitar a vida que já não existe mais e reconstruir novos signos no lugar. O território tem novos atores e é vigiado, densificado por técnicas e ciências. Já não são os saberes do cultivo em vazante que lhes proporcionam boas colheitas, mas o conhecimento de agrônomos no uso do solo de chapada e os saberes ribeirinhos que direcionam a plantação, o que nem sempre é uma troca de saber harmoniosa.

Compreendemos que a forma como esses sujeitos foram retirados das suas terras e a desterritorialização fortificaram a identidade de resistência e, depois de 10 anos, há permanências do modo de vida ribeirinha: nas culturas que cultivam a terra, fazem redes, pescam e comem o peixe.

\section{REFERÊNCIAS}

AB'SÁBER, A. Os domínios de natureza no Brasil: potencialidades paisagísticas. São Paulo: Ateliê Editorial, 2003. 
AQUINO, N. A. A construção da Belém-Brasília e suas implicações no processo de urbanização do estado do Tocantins. In: GIRALDIN, O. (org.). A (trans) formação histórica do Tocantins. Goiânia: Editora UFG, 2002. p. 315-350. BARBOSA, A. S.; GOMES, H.; TEIXEIRA NETO, A. Geografia Goiás / Tocantins. 2. ed. Goiânia: Editora UFG, 2005.

BONNEMAISON, J. L'Arbre et la Pirogue: les fondements s'une identité territoire, histoire et société dans l'archipel de Vanuatu (Mélanésie). Paris: Éditions de L'ORSTOM, 1986.

BONNEMAISON, J. Tanna. Les fondements géographiques d'une identité: les Gens des lieux. Histoire et géosymboles d'une société enracinée. Paris: Orstom, 1987.

BONNEMAISON, J. Viagem em torno do território. In: CORRÊA, R. L.; ROSENDAHL, Z. (org.). Geografia cultural: uma antologia. Rio de Janeiro: EdUERJ, 2012. v. 2. p. 279-304.

BRITO, E. P. O papel de Palmas na rede de integração regional. 2009. 255 f. Dissertação (Mestrado em Geografia) - Programa de Pós-Graduação em Geografia, Universidade Federal da Grande Dourados, Dourados, 2009.

BRITO, E. P. Itinerários de uma identidade territorial na invenção do ser tocantinense. Orientador: Maria Geralda de Almeida. 2016. 290 f. Tese (Doutorado em Geografia) - Programa de Pós-Graduação em Geografia, Universidade Federal de Goiás, Goiânia, 2016.

BRITO, E. P. Sobre os ribeirinhos tocantinenses: história e resistências.

Interespaço: revista de geografia e interdisciplinaridade, São Luiz, v. 4, n. 14, p. 33, out. 2018.

BRITO, E. P.; SHIMASAKI, M. M. Territórios e identidades dos ribeirinhos pescadores vazanteiros do rio Araguaia em Araguatins, Tocantins, Confins [Online], n. 48, 19 dez. 2020. Disponível em: http:// journals.openedition.org/confins/34236. Acesso em: 01 mar. 2021.

CESTE. Histórico. Consórcio Estreito Energia. 2016. Disponível em: http:/ / uhe-estreito.com.br/institucional/historico.html. Acesso em: 07 maio 2020.

CONCEIÇÃO, E. C. L.; BRITO, E. P. No itinerário da formação de Muricilândia-TO. Geografia em Atos, Presidente Prudente, v. 3, n. 10, p. 241 254, 1 abr. 2019. 
COSTA, D. P. Os camponeses da ilha de São José e a construção da Usina Hidroelétrica de Estreito: da terra de trabalho ao território do devir. 2019. 144 f. Dissertação (Mestrado em Geografia) - Programa de Pós-Graduação em Geografia, Universidade Federal do Tocantins, Porto Nacional, 2019.

CUNHA, L. H. O. Significados múltiplos das águas. In: DIEGUES, A. C. (org.). A imagem das águas. São Paulo: Hucitec, 2000. p. 15-26.

DIEGUES, A. C. Água e cultura nas populações tradicionais brasileiras. In: ENCONTRO INTERNACIONAL: GOVERNANÇA DA ÁGUA, 1., 2007, São Paulo. Anais [...]. São Paulo: NUPAUB, 2007. p. 01-10. Disponível em: http:/ / nupaub.fflch.usp.br/sites/nupaub.fflch.usp.br/files/color/simbolagua. pdf. Acesso em: 11 maio 2020.

GARZON, L. F. N.; SILVA, D. S. Remanescentes ribeirinhos pós-hidrelétricas: difícil re-existência. Boletim Observatório da Diversidade Cultural, Belo Horizonte, v. 2, n. 82, p. 20-26, mar. 2019. Disponível em: https://www. researchgate.net/publication/333004883. Acesso em: 08 maio 2020.

GOMES, H. Introdução à geografia de Goiás: a terra. São Paulo: s. n., 1966. 161 p.

HAESBAERT, R. "Gaúchos” no Nordeste: modernidade, des-territorialização e identidade. 1995. Tese (Doutorado em Geografia Humana) - Departamento de Geografia, Programa de Pós-Graduação em Geografia Humana, Universidade de São Paulo, São Paulo, 1995.

HOLZER, W. Lugar. Geographia, Niterói, v. 47, n. 21, p. 130-134, dez. 2019. Disponível em: https://periodicos.uff.br/geographia/article/ view/40757/23468. Acesso em: 12 maio 2020.

MACHADO, L. O. A fronteira agrícola na Amazônia brasileira. Revista Brasileira de Geografia, Rio de Janeiro, n. 54, p. 27-55, 1992. Disponível em: http:/ / biblioteca.ibge.gov.br/ biblioteca-catalogo.html?view $=$ detalhes\&id $=7115$. Acesso em: 18 jan. 2013.

MARTINS, J. S. O tempo da fronteira. Retorno à controvérsia sobre o tempo histórico da frente de expansão e da frente pioneira. Tempo Social, São Paulo, v. 8, n. 1, p. 25-70, maio 1996.

PALACÍN, L.; MORAES, M. A. S. História de Goiás (1722-1972). 6 ed. Goiânia: Editora da UCG, 2001. 
ROLDÃO, A. F.; FERREIRA, V. O. Climatologia do Estado do Tocantins - Brasil. Cadernos de Geografia, Belo Horizonte, p. 1161-1181, nov. 2019. Disponível em: http://periodicos.pucminas.br/index.php/geografia/article/ view/21629. Acesso em: 21 abr. 2020.

SCIOLLA, L. L'identità a più dimensioni: il soggetto e la transformazione dei legami sociali. Roma: Ediesse, 2010.

SILVA, G. O. Água, vida e pensamento: um estudo de cosmovisão entre trabalhadores da pesca: um estudo de cosmovisão entre trabalhadores da pesca. In: DIEGUES, A. C. A imagem das águas. São Paulo: Hucitec, 2000. p. 27-38. SIOLI, H. 50 anos de pesquisas em limnologia na Amazônia. Acta Amazônica, Manaus, v. 36, n. 06, p. 287-298, ago. 2006. Disponível em: http:/ / www.scielo.br/pdf/ /aa/v36n3/v36n3a01.pdf. Acesso em: 24 abr. 2018.

SOUSA, C. S. Mulheres que lavam no rio que enxágua: a permanência das lavadeiras no rio Araguaia em Xambioá - TO. 32 f. 2019. Trabalho de Conclusão de Curso (Graduação em Geografia) - Curso de Geografia, Universidade Federal do Tocantins, Araguaína, 2019.

TEIXEIRA NETO, A. O território goiano: formação e processo de povoamento e urbanização. In: ALMEIDA, M. G. A. (org.). Abordagens geográficas de Goiás: o natural e o social na contemporaneidade. Goiânia: Editora UFG, 2002. p. 9-31.

VALVERDE, O. Estudos de geografia agrária brasileira. Petrópolis: Vozes, 1985.

VALVERDE, O.; DIAS, C. V. A rodovia Belém-Brasília: estudo de Geografia Regional. Rio de Janeiro: Fundação Instituto Brasileiro de Geografia, 1967.

VERDEJO, M. E. Diagnóstico rural participativo: guia prático DRP. Brasília: MDA/Secretaria da Agricultura Familiar, 2006. 
